\title{
A Multimedia Integrated Learning Framework for Medical Education
}

\author{
Prof. Nishantha Giguruwa G.D., Ph.D. \\ Associate Professor, ICT Institute and Head, Digital Technologies Innovation Center, Ritsumeikan Asia Pacific \\ University, Beppu, Japan \\ E-Mail address: gamagelk@apu.ac.jp
}

Prof. Jayantha Weerasinghe, Ph.D.

Professor in Oral \& Maxillofacial Surgery, Faculty of Dental Sciences, University of Peradeniya

E-Mail address: juw@pdn.ac.lk

Prof. Yukuo Hayashida, Ph.D.

Professor and Dean, Faculty of Science and Engineering, Saga University, Saga, Japan

E-Mail address: hayasida@is.saga-u.ac.jp

Sri Lanka Journal of Bio-Medical Informatics 2011;2(3):86-101

DOI: http://dx.doi.org/10.4038/sljbmi.v2i3.3798

\begin{abstract}
In recent years, information and communication technology and multimedia technology have increasingly altered the landscape of the educational field particularly in higher education. In that, student is becoming the key focus of the educational process, where students' creativity and interactions are strongly encouraged through IT enabled systems. The learning management system (LMS) is the system responsible for integrating all learning services and managing teaching and learning activities. It provides a collection of tools and functions to support teaching and learning processes, usually including course management tools, online group discussion, homework collections and grading; and course evaluation. The amount of multimedia support facilitated by the e-learning systems has given significant consideration in order to make distance education as effective as classroom education and make the blended leaning experience more effective. While the technology is moving toward a multimedia rich learning management system, its practical deployments is still far away, due to many unsolved technical and pedagogical problems. In this paper we present a framework for implementing a content integrated learning management system with specific focus on multimedia enrichment in learning content. It can be used effectively for teaching courses in medicine as well as to support complementary education for clinicians through channels such as telemedicine which can be integrated as an important component of epidemiology. We discuss two implementation examples: (a) UMELMS implementation in Ritsumeikan Asia Pacific University, and (b) telemedicine implementation to support international medical collaboration to present our concept of new generation medical education system design.
\end{abstract}

Keywords - Learning Management System; Multimedia, Medical Education; Telemedicine; UMELMS

\section{Introduction}

IT enabled learning (e-learning) opens new dimensions for education ranging from simple file sharing systems that facilitate dissemination of didactic materials to sophisticated smart classrooms $^{(1)}$ that transfer technology and know-how cultivated through years of rigorous academic research from one location to many other locations. Recent advances in multimedia database technology, high performance networking, and fast content indexing mechanisms present an extraordinary opportunity to bring e-learning semantics to medical classrooms ${ }^{(2)}$ with enhanced search, discovery and presentation capabilities of multimedia medical information ${ }^{(3)}$. Starting from educational policy concern that online education initiatives could be justified on the basis of cost efficiency, or the need to provide access to learners in settings where face-to-face instruction is not feasible, today we face two predominant challenges namely: (a) enhancing the quality and accessibility of educational resources via means that adapts to the lifestyle's of learners, (b) enhancing the quality and volume of didactic materials to make the educational environment 
resourceful. Medical education can be benefited immensely by the above enhancements with the best blend of face-to-face classroom learning and distance education ${ }^{(4)}$.

In the context of medical education, information is not available in abundance. Limited availability of medical information is considered as a serious constraint both in basic and complementary education $^{(2)}$. In fact, the learners at all levels: medical students, trainees, nurses, technicians, and physicians are forced to operate in isolated and less resourceful environments when access to valuable medical information is limited. This also results in decreased access to education for practitioners. Hence, development of didactic materials to support medical education, via means such as teacher authoring, learner outcomes, and group sharing; plays an important role in Learning Management System (LMS) ${ }^{(5)}$. In addition to this problem of resource scarcity or lack of convenient accessibility to didactic materials, currently available LMS such as Blackboard, Moodle, and Claroline have not captured the lifestyles of the learners (and teachers) in the modern society in facilitating the learning environment. A current day learner is a dynamic character that is immersed in a networked society where he/she enjoys the state of the art technologies such as on-demand streaming, podcasting, and virtual avatars via social networks like YouTube, Twitter, and Facebook. Additionally, decreasing study efforts due to 'study while working' habits and increasing load of information opens a wide functional gap in current LMSs, placing a special demand on usercenteredness by which the user is motivated by the services of customised, intelligent, and adaptive services.

Authors have actively involved with a telemedicine programme between the Department of OMF Surgery of Saga University in Japan and Department of OMF Surgery of University of Peradeniya in Sri Lanka, since $2001^{(6)}$. This programme supported mainly three important activities to support international medical collaboration namely, (a) pre-surgery observation, (b) post-surgery observation, and (c) supporting the learning process (epidemiology) of new clinicians and sergeants joining the system. First two authors of this paper have experienced a rigorous process of designing a new generation $\operatorname{LMS}^{(7)}$ and have witnessed its success through a trial run in Ritsumeikan Asia Pacific University, in Japan. In this paper, the authors wish to consolidate their experience on medical collaboration systems and LMS to propose an effective blended learning environment for medical education. Authors' experience on the above activities will definitely provide the reader not only with knowledge on practical and cost effective solutions for open ended problems, but also on the authors' experience in custom tailoring an LMS with home grown technologies.

\section{Multimedia in e-learning}

As described by its name, multimedia is a combination of different forms of media that contains information stored at varying granularities of time and space resolution. For example, a still image can represent certain time of space with varying special resolutions, whereas an audio/video segment can represent both time and special information in continuous form at varying resolutions. Text on the other hand is human interpreted state of certain events or series of events in time and space. People understood the efficiency of using multimedia since a long time: surgery model has become standard equipment in the biology class, the molecular model is a standard equipment of chemistry, and there is no geographic lecture if there are no maps. Modern multimedia encompasses assimilation of more media forms to deliver its contents to the consumers in a highly usable manner, in that, people can make use of their multiple senses at the same time to grasp information quickly and accurately. Virtual reality and augmented reality technologies have enabled perceiving things even beyond the perception of human senses ${ }^{(8)}$. 


\section{Impact of multimedia in e-learning}

Use of multimedia in learning has been identified as an important element in LMS. High efficiency of using multimedia in education is caused by its characteristics, which include the following:

- Mirrors the way in which the human mind thinks, learns, and remembers

- The combination of media elements in a multimedia lesson enables trainees to learn more spontaneously and naturally, using whatever sensory modes they prefer, extending their experience to discover on their own, enable them with varying levels of literacy and mathematical skills to learn by using sight, hearing, and touch

- Multimedia programmes (expert systems) are designed to allow learners to pause, branch, or stop for further remediation, exploration, or enhancement opportunities; encouraging non-linear thinking

- Multimedia is the only viable and effective content format that could be used effectively for education due to study while working habits. Moreover multimedia contents result in enhanced viewing, reading, and listing experience for the users of mobile devices (ie. small screens, Bluetooth earphones, multi tough read pads etc.)

- The rapid development of mobile technology and decreasing mobile internet costs have dramatically increased mobile access to multimedia contents, enabling multimedia medical education affordable to majority of learners over the globe.

A study conducted by CERT $^{(9)}$ reveals a retention rate of approximately $20 \%$ of what we hear; $40 \%$ of what we see and hear; and $75 \%$ of what we see, hear, and do. Trainees can complete courses with multimedia in one-third of the time as those when receiving traditional instructions, and reach competency levels up to $50 \%$ higher. Furthermore, in most of the cases the overall cost of instructions is lower. According to a separate study, it is a known fact that the best way to ensure mastery and retention of a specific instructional subject is to present the subject to the user in multiple; increasingly-engaging formats. Students read about a topic, hear about it, see it, and then put it into practice. They can repeat any step until they feel comfortable with the material. A graphical presentation of this idea by CERT ${ }^{\circ}$ is shown in Figure 1. As can be observed, the subject mastery level continues to increase as one utilises more of his/her sensory powers. 


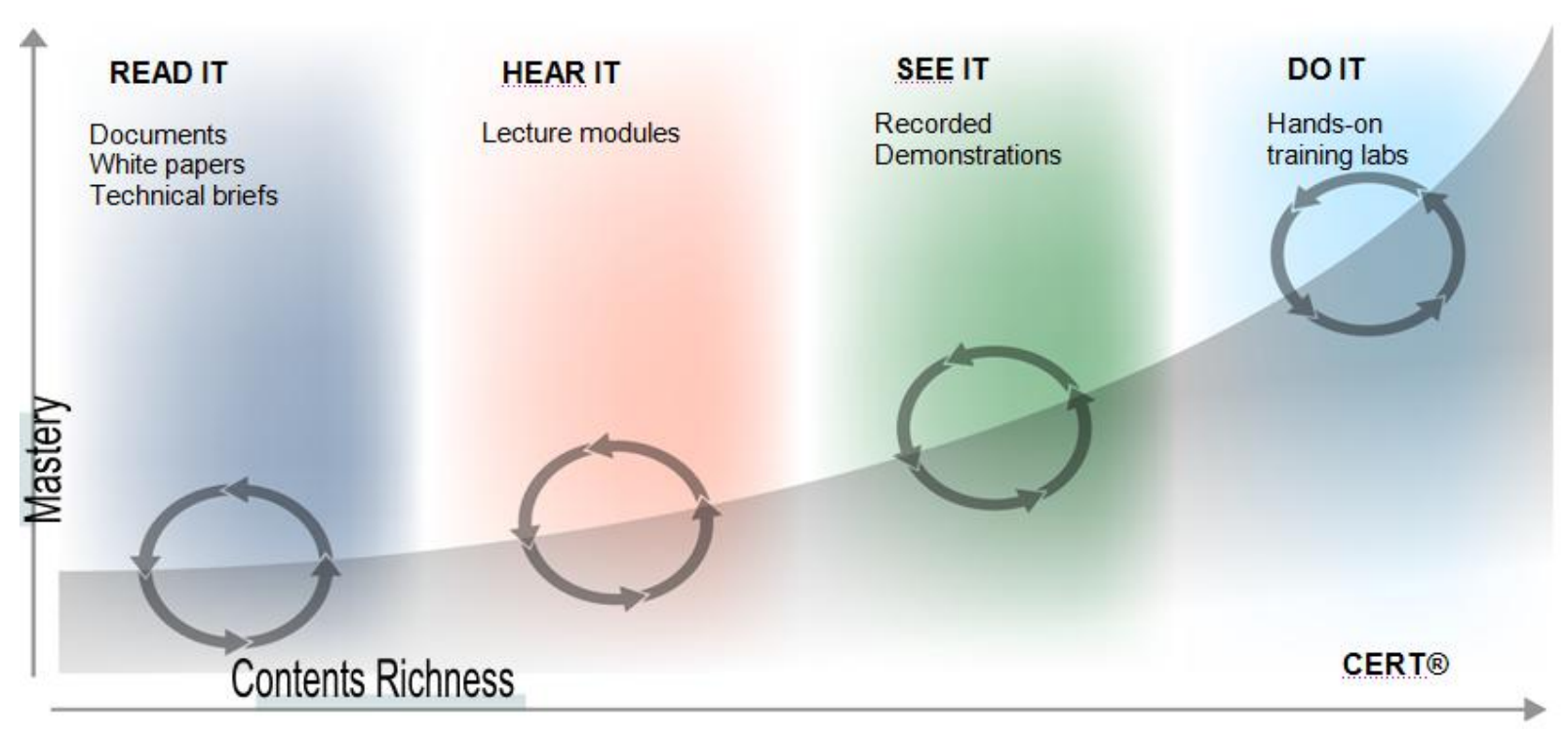

Figure 1. Multi-modal learning reinforcement in VTE

\section{Multimedia usage in current LMS}

Despite the mighty of multimedia content in didactic materials, its usage in learning management systems is still not straightforward due to many reasons. First, multimedia handling involves a large amount of computing power and storage volume requiring improvements to current equipment; second, multimedia dissemination requires high band-width links requiring costly investment for network improvements; third multimedia access gadgets are not readily available for all students, and fourth, teaching pedagogies have not yet captured the important semantics of multimedia based learning.

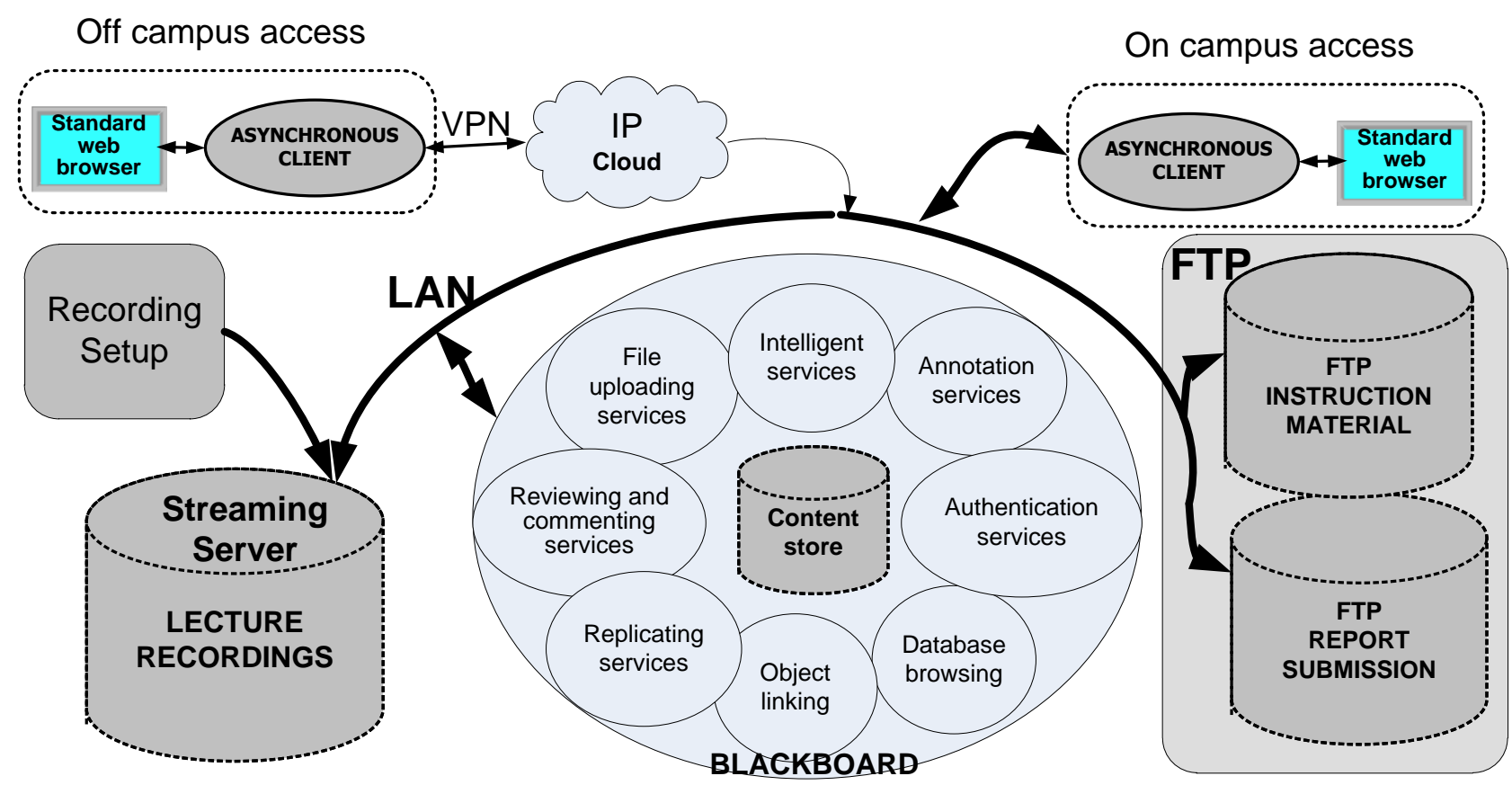

Figure 2. Components of the ICT based educational platform in APU 
Due to the reasons explained above, multimedia content usage in LMS is not popular yet. However, use of multimodal contents in education has been practiced in some universities by making use of conventional methods of file and media handling technologies bundled to existing LMS. For example, in Ritsumeikan Asia Pacific University in Japan, a tripartite model is used as illustrated in Figure 2 - a combination of FTP server, multimedia server, and blackboard has been serving this purpose for a decade ${ }^{(10)}$.

- FTP file server: File Transfer Protocol file server holds two sub-folders, Instructional Material and Submit Report for all lectures. Instructional Materials contain course contents while the Submit Report folder is used for students to submit their assignments

- WebCT/Blackboard system: From the year 2000 to 2007 APU used WebCT, a web-based course management system and in 2008, APU upgraded the LMS system to Blackboard ${ }^{(11)}$ because it was found to be more user-friendly and supports more functions. Presently, APU is still using Blackboard and the Blackboard site is accessible off campus requiring Virtual Private Network (VPN) for some specific pages

- Lecture recording and Multimedia streaming server: Class discussion and lectures can be recorded using a special mobile recording equipment set (fixed installation is limited to a few lecture rooms) and the recorded clips are uploaded to the multimedia streaming server that uses synchronous multimedia integration language (SMIL)

- Custom-made LMS: Some lectures in APU are using their own LMS. In the ICT institute in APU, the creators use a custom-made LMS, basically a modified version of Claroline, to best accommodate their teaching pedagogy

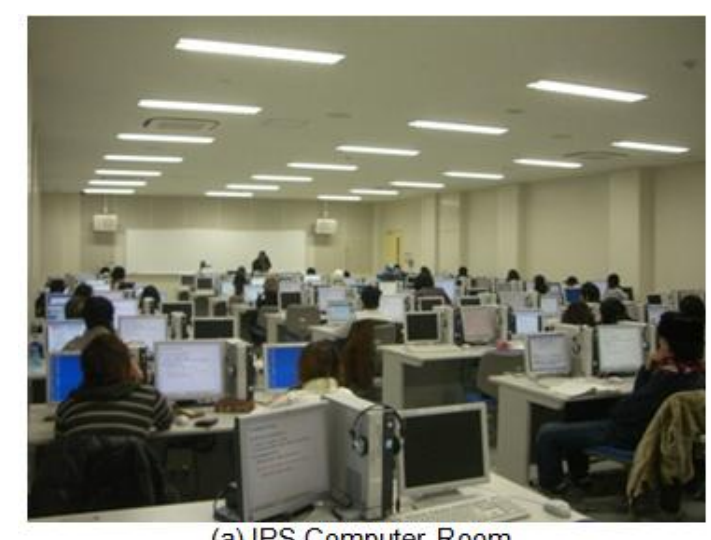

(a) IPS Computer Room

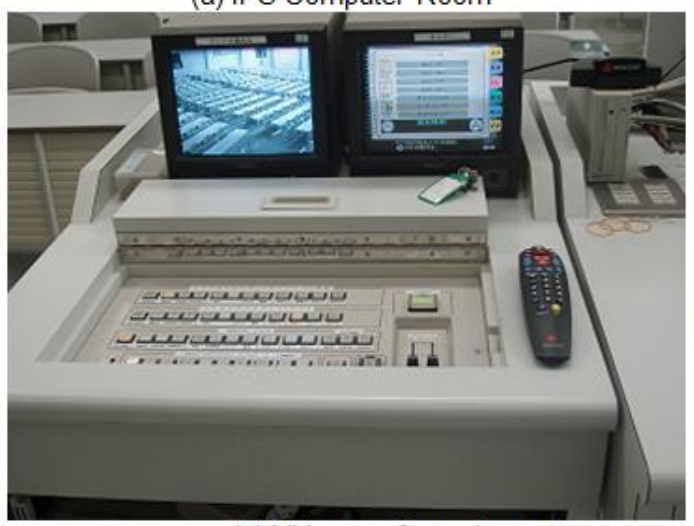

(c) Video conferencing setup

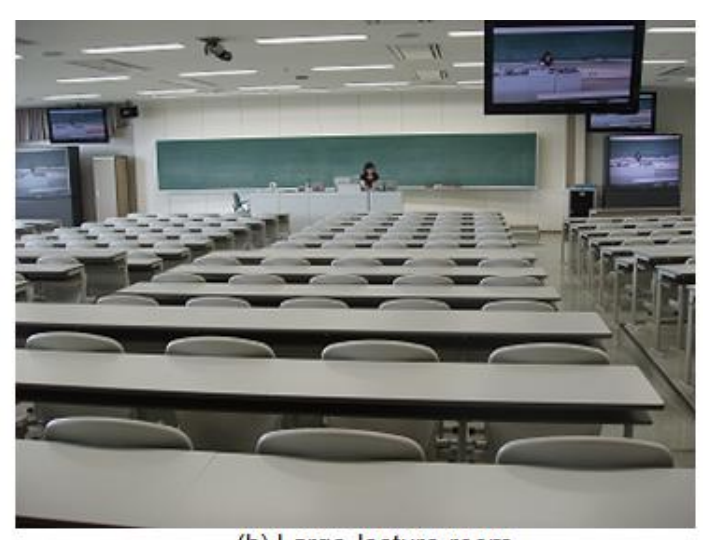

(b) Large lecture room

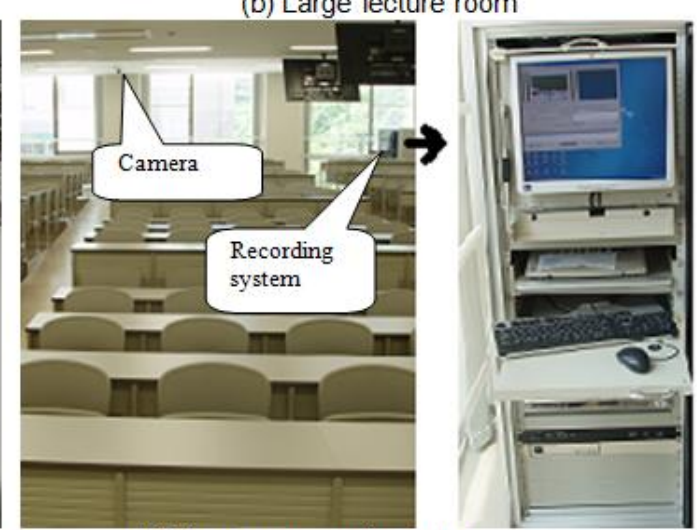

(d) Lecture recording setup

Figure 3. Classrooms and device setup in $A P U$ 
Table 1. APU Classrooms and Resources

\begin{tabular}{|c|c|c|c|c|c|}
\hline $\begin{array}{c}\text { Classroom } \\
\text { Type }\end{array}$ & No & $\begin{array}{c}\text { Instructor's Desk } \\
\text { Setup }\end{array}$ & $\begin{array}{l}\text { Presentation } \\
\text { Screens }\end{array}$ & $\begin{array}{l}\text { No. of } \\
\text { PCs }\end{array}$ & $\begin{array}{c}\text { Coursed } \\
\text { Conducted }\end{array}$ \\
\hline $\begin{array}{l}\text { IPS } \\
\text { (Information } \\
\text { Processing } \\
\text { Study) } \\
\text { rooms }\end{array}$ & 9 & $\begin{array}{l}\text { A PC attached to a desk } \\
\text { with AV devices and } \\
\text { document camera. (Some } \\
\text { classrooms are equipped } \\
\text { with a video conferencing } \\
\text { set.) }\end{array}$ & $\begin{array}{l}\text { Every two } \\
\text { students share } \\
\text { one LCD } \\
\text { screen on the } \\
\text { desk }\end{array}$ & $\begin{array}{l}\text { Lecturer } \\
1 \mathrm{PC} \\
\text { Students } \\
70 \text { PCs }\end{array}$ & $\begin{array}{l}\text { Foundation IT } \\
\text { courses } \\
\text { ICT courses } \\
\text { MIS courses }\end{array}$ \\
\hline $\begin{array}{l}\text { CAI } \\
\text { (Computer } \\
\text { Assisted } \\
\text { Instruction) } \\
\text { rooms }\end{array}$ & 21 & $\begin{array}{l}1 \text { PC (with provision to } \\
\text { connect a note- PC), well } \\
\text { equipped multimedia } \\
\text { desk with AV devices } \\
\text { and document camera. }\end{array}$ & $\begin{array}{l}\text { Every two } \\
\text { students share } \\
\text { one LCD } \\
\text { screen on the } \\
\text { desk }\end{array}$ & $\begin{array}{l}\text { Lecturer } \\
1 P C \\
\text { Students } \\
25 \text { PCs }\end{array}$ & $\begin{array}{l}\text { Language } \\
\text { Courses } \\
\text { Selected } \\
\text { Management } \\
\text { Courses }\end{array}$ \\
\hline $\begin{array}{l}\text { Seminar } \\
\text { rooms }\end{array}$ & $\sim$ & $\begin{array}{l}1 \text { PC (with provision to } \\
\text { connect a note- book), well } \\
\text { equipped multimedia } \\
\text { desk with AV devices } \\
\text { and docu- ment camera. }\end{array}$ & $\begin{array}{l}\text { One large } \\
\text { screen }\end{array}$ & $\begin{array}{l}\text { Lecturer } \\
1 \mathrm{PC} \\
\text { Students } \\
0 \text { PCs }\end{array}$ & $\begin{array}{l}3 \text { rd year general } \\
\text { seminar }\end{array}$ \\
\hline $\begin{array}{l}\text { ICT } \\
\text { Seminar } \\
\text { Rooms }\end{array}$ & 10 & $1 \mathrm{PC}$ & Students PCs & $\begin{array}{l}\text { Lecturer } \\
1 \mathrm{PC} \\
\text { Students } \\
8 \text { PCs } \\
\end{array}$ & $\begin{array}{l}3^{\text {rd }} \text { year seminar } \\
4^{\text {th }} \text { year } \\
\text { graduation } \\
\text { research seminar }\end{array}$ \\
\hline $\begin{array}{l}\text { Large } \\
\text { Lecture } \\
\text { Rooms }\end{array}$ & 6 & $\begin{array}{l}1 \text { PC (with provision to } \\
\text { connect a note-PC), well } \\
\text { equipped Multimedia } \\
\text { Desk with AV devices } \\
\text { and document camera. }\end{array}$ & $\begin{array}{l}\text { Multiple large } \\
\text { screens }\end{array}$ & $\begin{array}{l}\text { Lecturer } \\
1 \mathrm{PC} \\
\text { Students } \\
0 \text { PCs }\end{array}$ & $\begin{array}{l}\text { Foundation } \\
\text { courses (general, } \\
\text { (that do not use } \\
\text { PCs) }\end{array}$ \\
\hline
\end{tabular}

Availability of classroom equipment is very much influential to the state of the art learning systems that can be used in classroom environments. This involves classroom resources ranging from simple availability of presentation projectors to sophisticated smart classroom settings. Figure 3 illustrates smart classrooms setup at some selected lecture rooms at APU. A summary of classroom resources in APU are given in Table 1. Above details clarify that there are many classrooms remaining which are not well-equipped.

While the LMS technology is moving towards a multimedia rich learning management system, its practical deployments is still far away, due to many unsolved technical and pedagogical problems. It required a customised approach to support different course modules. We borrow from our experience in Multimedia medical collaboration ${ }^{(6)}$, and design of multimedia supported education systems $^{(12)}$ which can jointly facilitate an enhanced medical education environment that can operate even at low resource settings.

\section{Multimedia Integrated e-Learning Framework}

In devising the integrated framework for LMS implementation, requirement of all stake holder groups are to be addressed by providing a multitude of functions to realise the intended LMS - a user-centric, customized, content rich, and ubiquitous learning environment. All these functions ensure a leaning environment with; (a) reduced cost and time consumption, (b) reduced workload, 
(c) enhanced educational quality, (d) enhanced system accessibility, and (e) enhanced usability. This section elaborates the integral components of multimedia integrated framework ${ }^{(13)}$ design namely; input integration, content generation, and access integration scenarios as well as the state of the art technologies that can be used to accomplish this task.

\section{LMS content model}

Figure 4 illustrates didactic content and its associated access scenarios pertaining to LMS over a generic course life cycle, indicating the interaction of its stakeholders (ie. administrators, teachers and lectures). Involvement of multimedia in this model covers major portion of content volume and plays a significant role in supporting the learner and teacher in understanding the course content, evaluating students' progress, report back to the lecturer, and participate in group discussions etc. Since continuous multimedia can only be made useful only if the user can spend the required time duration for playback, multimedia content should always reach users with high availability both in time and space. On the other hand adequate metadata should be embedded in multimedia to maximise usage of the content through functions such as book marking, cross linking, and fast navigation.

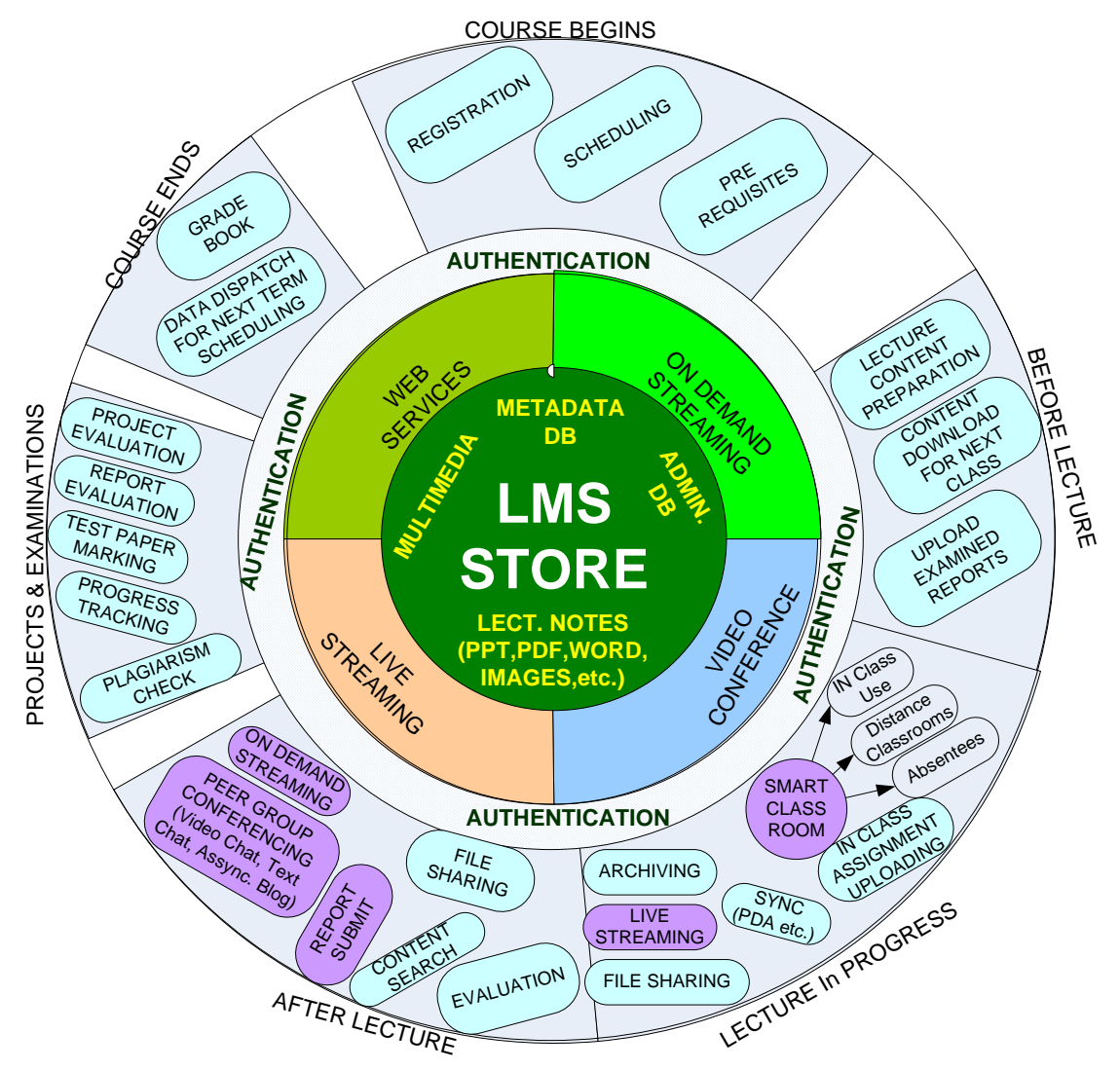

Figure 4. Content model and access scenarios for a course life cycle in integrated LMS 


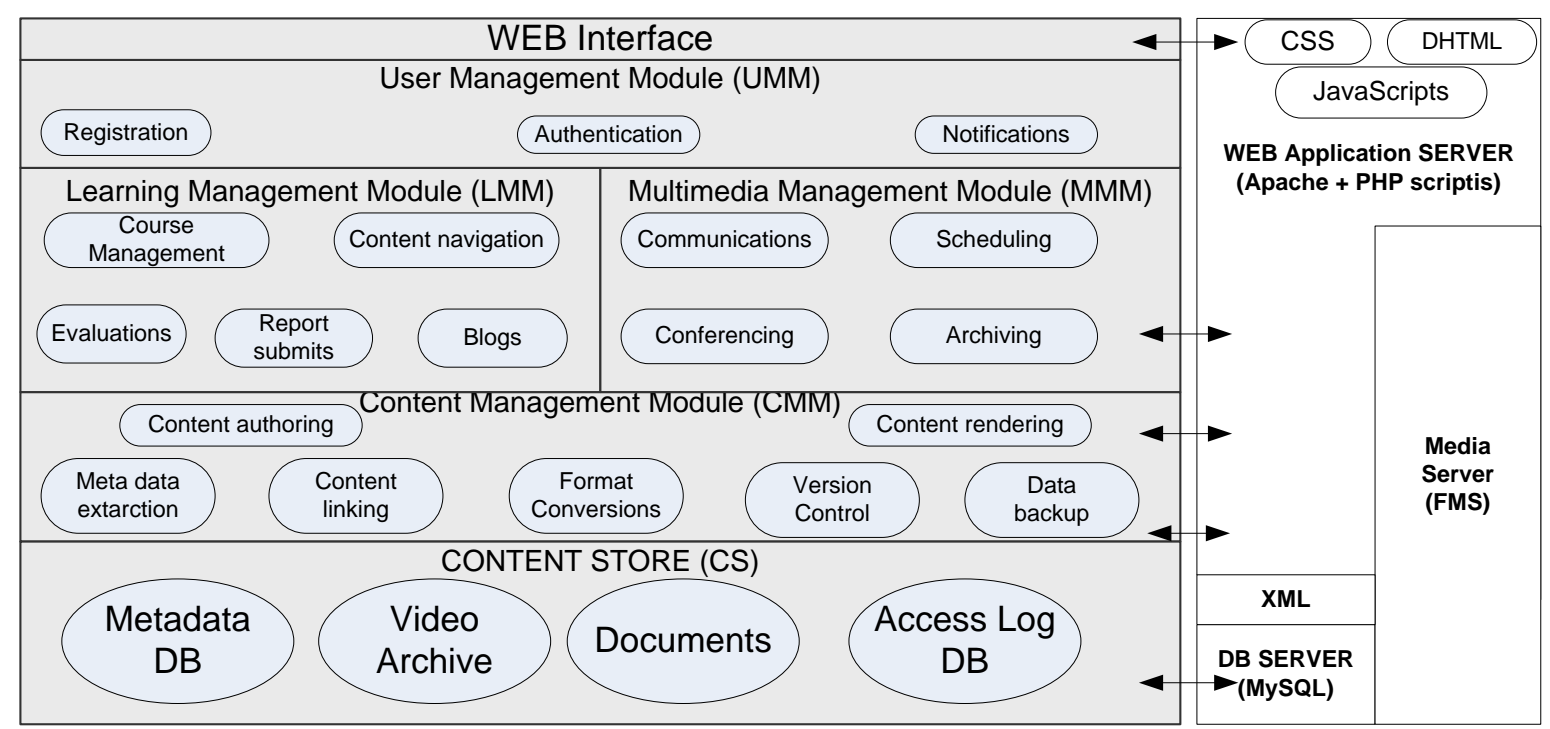

Figure 5. Modular architecture of the proposed LMS

\subsection{Integrated framework architecture}

Proposed framework essentially addresses several important design aspects though a modular design approach is taken to give flexibility to interact with other modules.

Figure 5 illustrates this modular architecture with corresponding implementation technologies shown on the right side of the diagram. Content Store (CS) is the storage for all content in hard disk as files and in database format with required backup and synchronising support. Content Management and Integration Module (CMIM) is responsible for content management functions such as authoring, versioning etc. Two separate modules that operates on top of CMIM are dedicated for input and output functionalities namely; Learning Management Module (LMM) to support various learning/teaching scenarios and learning Multimedia Management Module (MMM) to house functionality to handle ingest of multimedia into the system and related communication metaphors. User Management Module (UMM) is indispensable to manage the front office of the system such as registration, authentication, and notifications. UMM manages users as well as user groups and provides access authorisation to the system resources through the functional modules LMM and MMM. It also passes very important parameters to its underlying service interfaces on the access behaviour of users that makes sophisticated user-centric implementation possible. This modular design enables interfacing with complementary modules that the authors as proposes as separate work such as project management and evaluation system ${ }^{(14)}$, to promote student industrial internship programme (SIIP) ${ }^{(15)}$. Above modules can be integrated to implement a ubiquitous multimedia enhanced leaning management system with essentially three integration modules (a) input integration, (b) content integration, and (c) access integration which are explained in detailed in this section.

\section{Multimodal Integration}

Input integration refers to capturing various multimedia inputs to enhance the richness of lecture contents. Following multimedia input methods are of major concern for maximising multimedia effects in teaching as well as learning. The multimedia framework that we envisage integrates different sources of multimedia into LMS in three ways, as explained in 
Table 2 and illustrated in Figure 6.

Table 2. Multimodal input scenarios

\begin{tabular}{|c|c|}
\hline Method of Integration & Integration Scenarios \\
\hline \multirow{5}{*}{$\begin{array}{l}\text { Input Integration: } \\
\text { Method by which } \\
\text { multimedia can be } \\
\text { ingested into the LMS } \\
\text { storage or retrieved } \\
\text { from LMS. Multimedia } \\
\text { ingestion to the LMS } \\
\text { archive may occur in } \\
\text { many forms. }\end{array}$} & $\begin{array}{l}\text { Lecture recording: The recording mechanism essentially involves } \\
\text { multiple video inputs, multiple audio inputs, and PC screen captures } \\
\text { which forms a multi-layer video stream that captures all important } \\
\text { activities of the classroom. }\end{array}$ \\
\hline & $\begin{array}{l}\text { User side recording: A client side recording solution that facilitates } \\
\text { users with an interface to upload live audio/video recorded clips } \\
\text { enabling multimedia form of reporting possible. }\end{array}$ \\
\hline & $\begin{array}{l}\text { Live conferencing: Session recording in video conferencing (lectures, } \\
\text { telemedicine sessions) is supported by multi-layer video codec facility. }\end{array}$ \\
\hline & $\begin{array}{l}\text { Multimedia Blogs: All form of content that appear in blogs (text, } \\
\text { images, video) serves as vital input to LMS. }\end{array}$ \\
\hline & $\begin{array}{l}\text { Social Networking Systems: multimodal-information extractable from } \\
\text { SNS such as Facebook, twitter in respective discussion rooms serves as } \\
\text { vital input to LMS. }\end{array}$ \\
\hline \multirow{3}{*}{$\begin{array}{l}\text { Content Integration: } \\
\text { This is by which } \\
\text { different form of } \\
\text { multimedia interacts } \\
\text { with main course. }\end{array}$} & $\begin{array}{l}\text { Cross referencing: All forms of multimedia ingested into the system } \\
\text { are logged as events in the system for cross reference. For example an } \\
\text { audio report upload is properly linked to the assignment page with } \\
\text { timestamps. }\end{array}$ \\
\hline & $\begin{array}{l}\text { Multimedia tagging: This involves embedding metadata (eg. captions } \\
\text { and tagging) of lecture recordings through which each page can be } \\
\text { accessed quickly by using search option. }\end{array}$ \\
\hline & $\begin{array}{l}\text { Semantic Linking: This is a methodology proposed by the authors that } \\
\text { imparts fluid-level content navigation support. }\end{array}$ \\
\hline \multirow{7}{*}{$\begin{array}{l}\text { Access Integration: By } \\
\text { enabling a wide array of } \\
\text { mobile devices to } \\
\text { participate actively in } \\
\text { the LMS creates a real } \\
\text { u-learning environment. }\end{array}$} & $\begin{array}{l}\text { Synchronous access: Access to content takes simultaneously to } \\
\text { physical/virtual classroom activities. }\end{array}$ \\
\hline & $\begin{array}{l}\text { Asynchronous access: Access to content occurs outside the duration of } \\
\text { physical/virtual classroom activities. }\end{array}$ \\
\hline & $\begin{array}{l}\text { In class access: Synchronous access to contents inside the classroom is } \\
\text { the mostly used access format at present. }\end{array}$ \\
\hline & $\begin{array}{l}\text { Outside class access: This type of access may be either synchronous or } \\
\text { asynchronous and supports as any time anywhere access. }\end{array}$ \\
\hline & Access by PCs: All content can be accessed using PCs. \\
\hline & $\begin{array}{l}\text { Access by smart phones: Most of the content can be accessed via state } \\
\text { of the art smart phones. }\end{array}$ \\
\hline & $\begin{array}{l}\text { Access by other devices: Support for devices such as digital pen } \\
\text { systems (O-RID Kyber), networked video devices is also a necessity } \\
\text { for immerging systems. }\end{array}$ \\
\hline
\end{tabular}




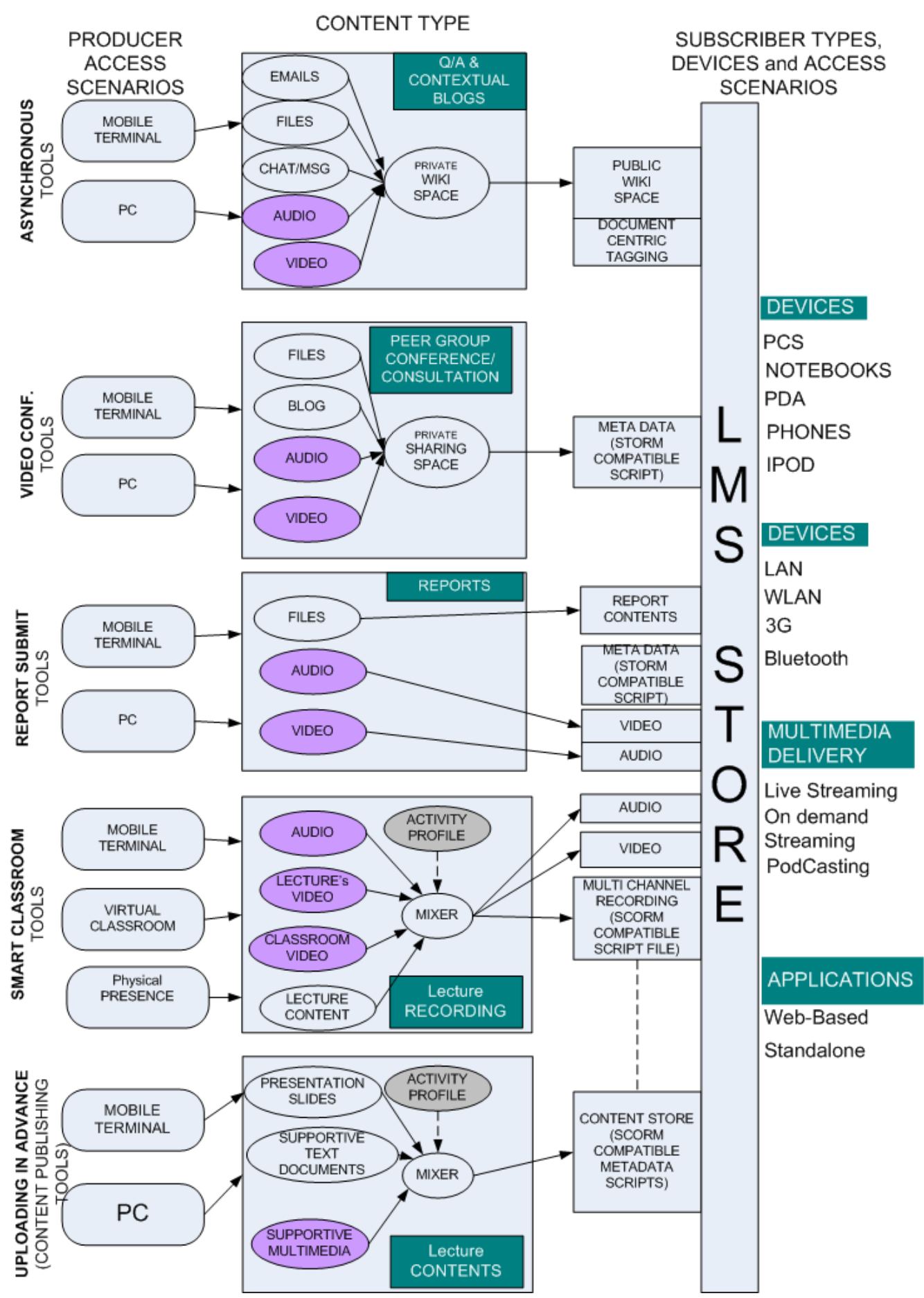

Figure 6. A generic multimedia-enhanced u-learning frameworks for LMS

\section{Content integration}

Having built up the content store with a mixture of related hypermedia elements (ie. lecture contents, lecture recording, report submissions and client side multimedia) it is required to relate different elements for enhanced accessibility. We adopt a metadata model to implement a semantic linking mechanism as presented elsewhere ${ }^{(16)}$ to relate different elements in the LMS store. The content model we adopt allows context aware navigation rather than conventional hierarchical 
browsing. This context aware navigation enables flexible content view such as lecturer centric, student centric, course centric and activity centric as illustrated in Figure 7.

The students/lectures are given an interface to store the contents in an interrelated way using semantic cross-links such that the content navigation becomes easier and faster. Different elements inherit relations are based on the context that it creates. The need for creating manual links is avoided as far as possible. The access rights are also defined by the time the object is created on contextual grounds. The lecturer/course admin is given the authority to override these access controls.

\section{Course Thread: Generic Course}

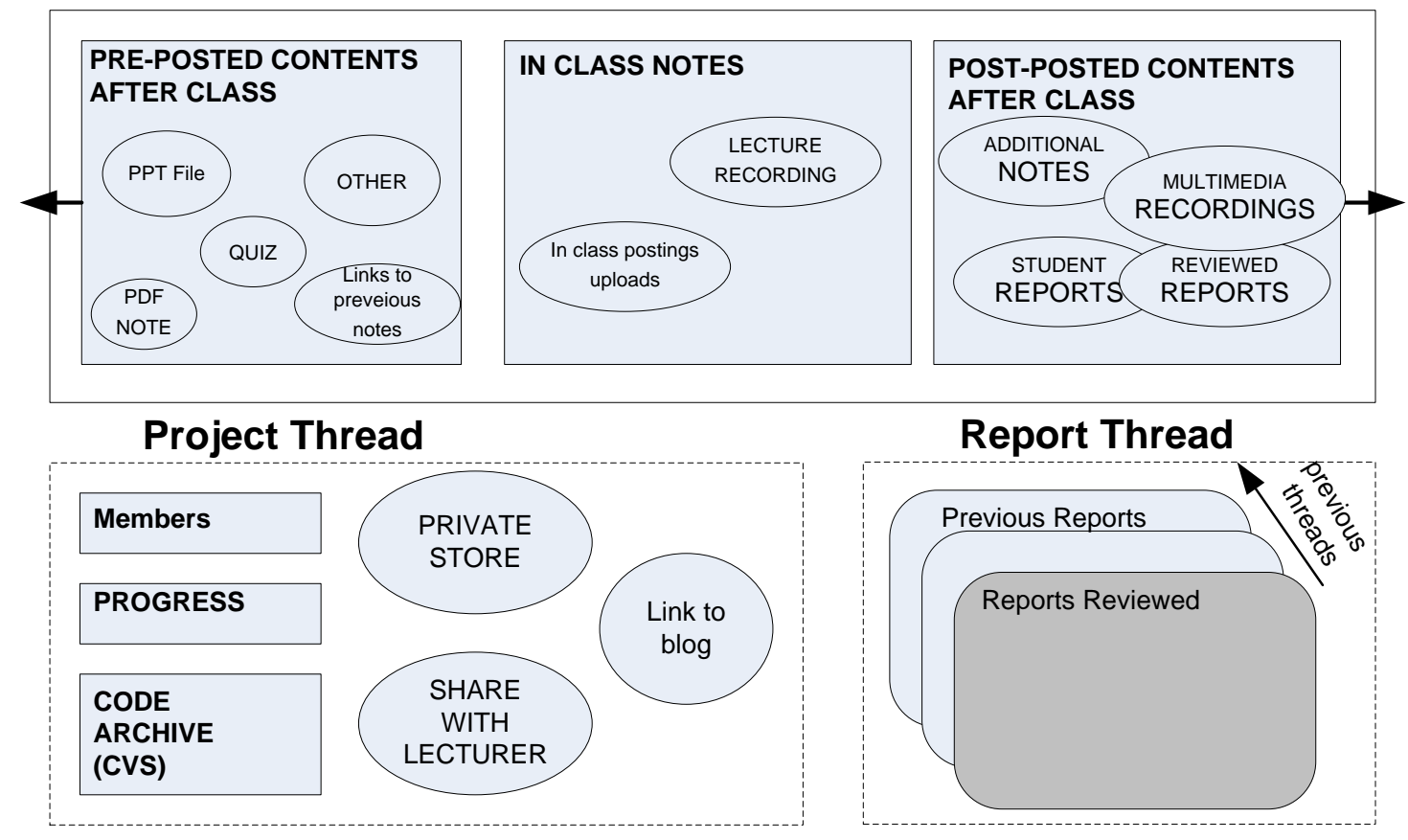

Figure 7. Schematic of the integrated content model. (Relate this to SCO

\section{Telemedicine System Experience: \\ High-quality Image Transmission and Promoting Epidemiology}

Well before the multimedia enhanced LMS was implemented UMELMS ${ }^{13}$, authors implemented a fully customised version of the same model for telemedicine ${ }^{(17)}$. The Department of Oral and Maxillofacial Surgery of Faculty of Dental Sciences, University of Peradeniya in Sri Lanka has been conducting Training and collaborative skill development programmes for local and overseas surgeons. These programmers necessitated frequent visits by Medical experts of Saga University, Japan and other overseas resource centres. The incapability of existing commercial and academic groupware to support telemedicine between Sri Lanka and Japan motivated the authors of the Department of Information Science of Saga University to develop a novel collaboration system; using the peer-to-peer collaboration system developed by the authors as able to transmit patient information before, during and after surgical treatment sessions between overseas experts and local surgeons which has improved the success of these training programmers.

At PGIM, attached to University of Colombo in Sri Lanka, the MSc Biomedical Informatics training programme facilitated by the University of Oslo is also conducted through distance learning modules and delivery of lectures by overseas tutors often using Skype. There is a need to 
transform some of the content of this curriculum to a content management system for which the authors have been considering possible customisations of their UMELMS concept.

\section{Usage scenarios in telemedicine sessions}

To support international medical collaboration activities carried out in Japan, Sri Lanka and other countries in Asia, we have been developing a collaboration system, which incorporates synchronous and asynchronous collaboration paradigms through network effective persistent information sharing. The designed system facilitates synchronous collaborative work on maxillofacial cases through real-time high-quality image delivery and bringing the system database objects to a sharedworkspace. The asynchronous activities are supported through a web based collaboration environment that enables both activity centric and object centric navigation of collaboration contents incorporated with e-mail notifications of system updates. Multimedia records of synchronous sessions are posted to the system database for later reviewing. Geographically dispersed groups experiencing different scales of network heterogeneities are served by a distributed application level multicast overlay and adaptive multimedia delivery mechanism. The designed collaboration system also features several useful collaboration tools, user friendly GUI and ubiquitous connectivity. A GUI snapshot of the multimedia group medical collaboration system is illustrated in Figure 8.

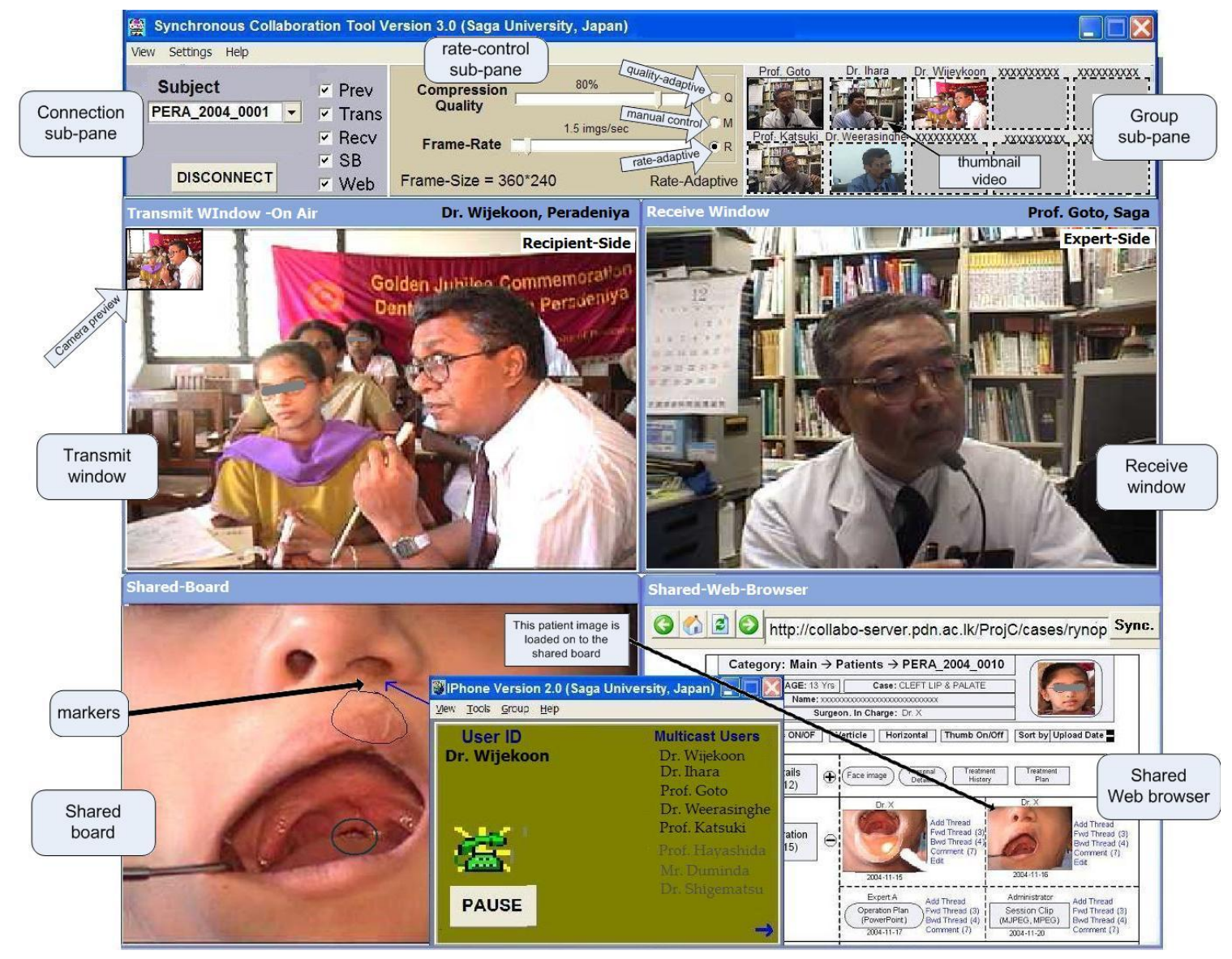

Figure 8. GUI snapshot of a synchronous session

Apart from synchronous sessions, the other facility available in this system is the asynchronous collaboration support. A snapshot of the asynchronous collaboration page with patient details displayed is illustrated in Figure 9. This allows the members to access the database at any time from any computer, and upload, browse or annotate documents. The support of this system is mainly 
three fold: (1) it acts as persistent database which could be reviewed later easily following e-mail notifications as well as the semantic links provided for cross referencing. Collaborators who missed the synchronous sessions as well as those who require reviewing past records find this system very useful; (2) Collaborators could work asynchronously at individual free time slots; (3) Bulk data (high quality patient images, images of radiographs, voice clips etc.) that would take a longer time to transmit during synchronous sessions could be uploaded to the database asynchronously for use during synchronous sessions without any time lag. Thread activities managed by semantic linking is depicted by Figure 10.

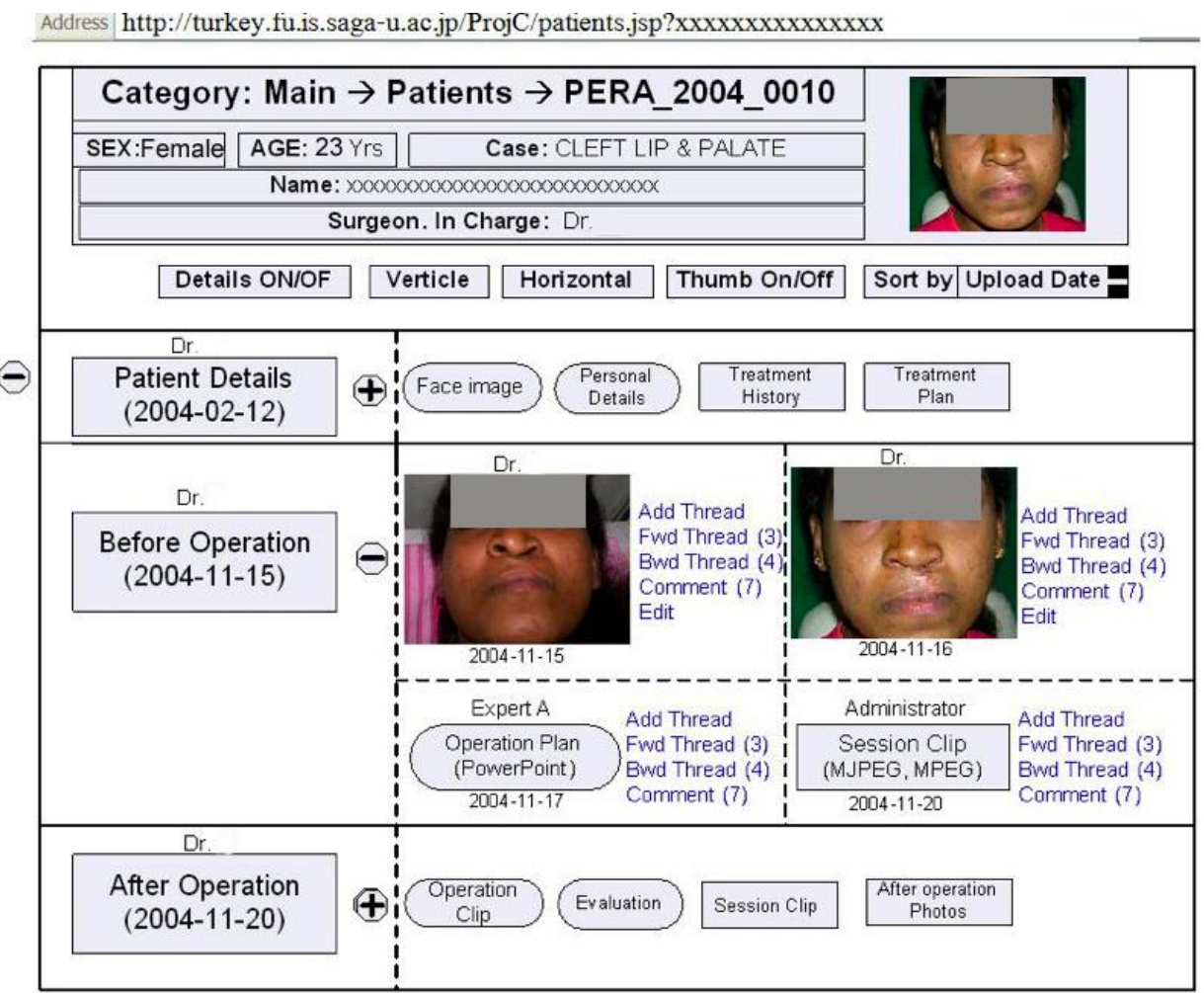

Figure 9. A sample of a customised page view accessed by an asynchronous client 


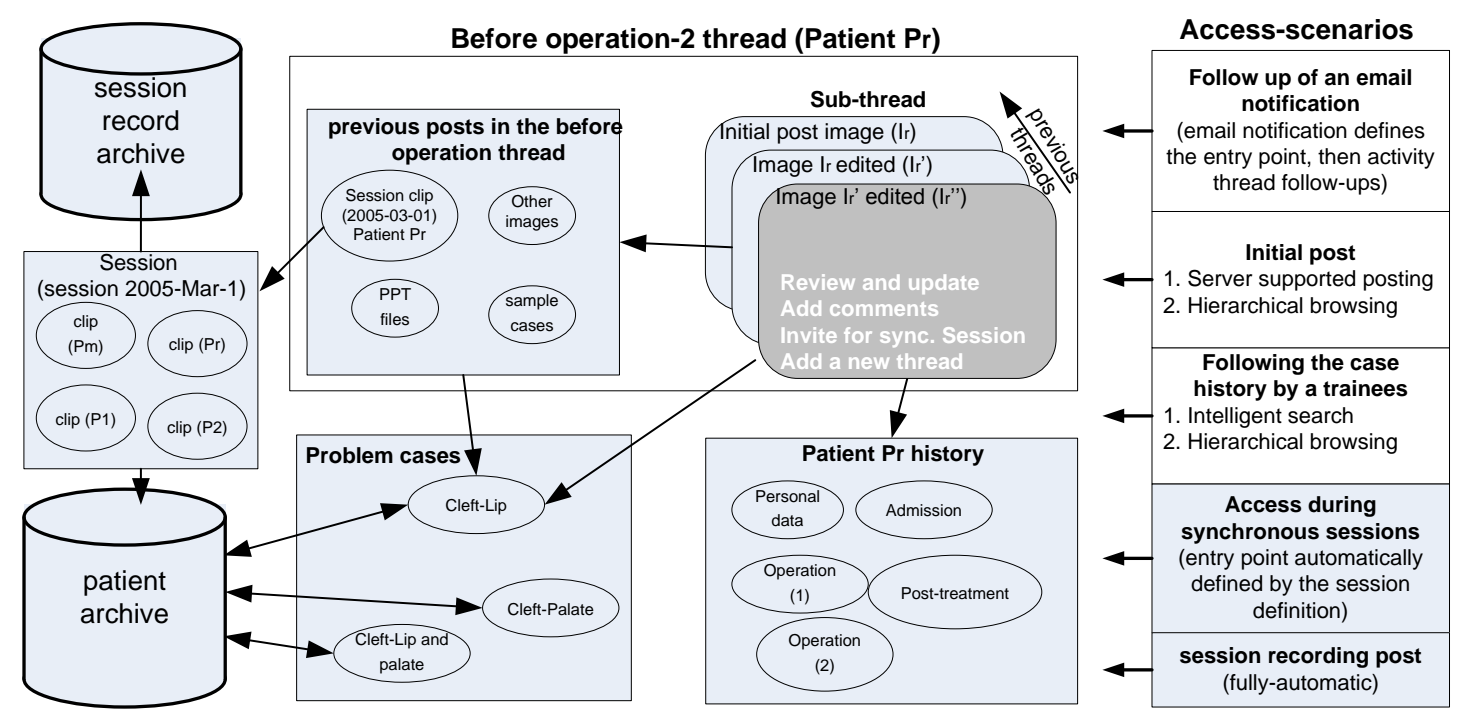

Figure 10. Schematic of object linkage and access scenarios: Medical collaboration trial

\section{Conclusion}

In this paper we presented a framework for implementing a content integrated learning management system with specific focus on multimedia enrichment in learning content. It can be used effectively for teaching courses in medicine as well as to support complementary education for clinicians through channels such as telemedicine which can be integrated as an important component of epidemiology. In this chapter two implementation examples are presented: (a) UMELMS implementation in Ritsumeikan Asia Pacific University, and (b) telemedicine implementation to support international medical collaboration. The authors believe that the concept of UMELMS and synchronous/asynchronous medical collaboration aspects discussed in this paper provide insight to new generation medical education systems.

\section{References}

1. Pishva D and Nishantha GGD. Smart classrooms for distance education and their adoption to multiple classroom architecture. Journal of Networks (JNW) 2008; 3(5): 54-64. doi:10.4304/jnw.3.5.54-64

2. Curta C and Ciupa RV. E-learning in medical related fields. Proceedings of the $7^{\text {th }}$ International Symposium on Advanced Topics in Electrical Engineering (ATEE); 2011. pp. 1-4

3. Mular H. Medical multimedia retrieval 2.0. Year book of medical informatics. International Medical Information Association (IMIA), Switzerland; 2008

4. Konstantinidis ST, Bamidis PD, and Kaldoudi E. Active blended learning in medical education: Combination of WEB 2.0 problem based learning and computer based audience response systems. Proceedings of the 22nd IEEE International Symposium on ComputerBased Medical Systems (CBMS); 2009. pp. 1-6

5. Bersin J, Howard C, and Leonard KO. Learning Management Systems 2008: Facts, Practical Analysis, Trends and Vendor Profiles. Bersin and Associates Learning Leaders ${ }^{\circledR} ; 2008$ 
6. Nishantha GGD, Anh DH, Pishva D, Claster WB, and Hayashida Y. Towards Developing an Integrated Multimedia Framework for Enhanced e-Learning. Proceedings of the $1^{\text {st }}$ International Conference on Computer Supported Education (CSEDU), Lisboa, Portugal, March 23-26; 2009. pp. 267-272

7. Anh DH, Nishantha GGD, Hayashida Y, and Davar P. A flash-based lecture recording system and its integration with LMS. Proceedings of the $12^{\text {th }}$ International Conference on Advanced communication technology (ICACT), 7 10 Feb, Phoenix Park, Gangwon-Do, Korea; 2010. pp. $1425-1429$

8. Oblinger D. Introduction to multimedia in instruction. Maximizing multimedia: A how-tosession for faculty, Dallas County Community College District at Dallas; 2007

9. CERT Virtual Training Environment, 2012 [homepage on the Internet]. Available from: http://www.cert.org/training/vte_description.html - Accessed 12-12-2011

10. Nishantha GGD, Mack L, and Pishva D. Current usage and future trends of learning management systems: a case study in Asia Pacific University. Proceedings of the INTED; 2009. pp. 948-958

11. Blackboard LMS [homepage on the Internet]. Available from: http://www.blackboard.com/ Accessed: 01-02-2012

12. Nishantha GGD, Hayashida Y, Katsuki T, Goto M, Ihara K, Weerasinghe J. A groupware design for supporting international medical collaboration over the internet. 2005, pp. 155-164

13. Nishantha GGD, Anh DH, Pishva D, and Claster WB. Multimedia enhanced ubiquitous learning management system. 2009, pp. 937-947

14. Nishantha GGD, Pishva D, and Hayashida Y. Design and implementation of a project evaluation and management system (PEMS) for supporting blended learning. presented at the Asia Pacific Conference: Outlook for the Asia Pacific, Beppu, Japan, 2010

15. Tanaka R, Nishantha GGD, Hayashida Y. Web-based expert learning system for student industrial internship. Proceedings of the $4^{\text {th }}$ International Conference on e-Learning, University of Toronto, Toronto, Canada, 16-17 July, 2009

16. Hita H, Nishantha GGD, Hayashida Y. A file system with semantic links for supporting asynchronous collaboration (Japanese). In IEICE regional conference, Kyushu-branch, Fukuoka, Japan; 2005

17. Nishantha GGD, Hayashida Y, Katsuki T, Goto M, Ihara K, and Weerasinghe J. A system for international telemedicine through integrated synchronous/asynchronous collaboration. IEICE Transactions, 2008; 89-D(1). 1: pp. 271-280. doi:10.1093/ietisy/e89-d.1.271 